\title{
Vegetable and fruit consumption and lung cancer risk in the Netherlands Cohort Study on diet and cancer
}

Citation for published version (APA):

Voorrips, L. E., Goldbohm, R. A., Verhoeven, D. T. H., van Poppel, G. A. F. C., Sturmans, F., Hermus, R. J. J., \& van den Brandt, P. A. (2000). Vegetable and fruit consumption and lung cancer risk in the Netherlands Cohort Study on diet and cancer. Cancer Causes \& Control, 11, 101-115. https://doi.org/10.1023/A:1008906706084

Document status and date:

Published: 01/01/2000

DOI:

10.1023/A:1008906706084

Document Version:

Publisher's PDF, also known as Version of record

\section{Please check the document version of this publication:}

- A submitted manuscript is the version of the article upon submission and before peer-review. There can be important differences between the submitted version and the official published version of record.

People interested in the research are advised to contact the author for the final version of the publication, or visit the DOI to the publisher's website.

- The final author version and the galley proof are versions of the publication after peer review.

- The final published version features the final layout of the paper including the volume, issue and page numbers.

Link to publication

\footnotetext{
General rights rights.

- You may freely distribute the URL identifying the publication in the public portal. please follow below link for the End User Agreement:

www.umlib.nl/taverne-license

Take down policy

If you believe that this document breaches copyright please contact us at:

repository@maastrichtuniversity.nl

providing details and we will investigate your claim.
}

Copyright and moral rights for the publications made accessible in the public portal are retained by the authors and/or other copyright owners and it is a condition of accessing publications that users recognise and abide by the legal requirements associated with these

- Users may download and print one copy of any publication from the public portal for the purpose of private study or research.

- You may not further distribute the material or use it for any profit-making activity or commercial gain

If the publication is distributed under the terms of Article $25 \mathrm{fa}$ of the Dutch Copyright Act, indicated by the "Taverne" license above, 


\title{
Vegetable and fruit consumption and lung cancer risk in the Netherlands Cohort Study on Diet and Cancer
}

\author{
Laura E. Voorrips ${ }^{1, *}$, R. Alexandra Goldbohm ${ }^{1}$, Dorette T.H. Verhoeven ${ }^{1}$, Geert A.F.C. van Poppel ${ }^{1}$, \\ Ferd Sturmans ${ }^{2}$, Rudolph J.J. Hermus ${ }^{1} \&$ Piet A. van den Brandt ${ }^{2}$ \\ ${ }^{1}$ Department of Nutritional Epidemiology, TNO Nutrition and Food Research Institute, PO Box 360, 3700 AJ Zeist, \\ The Netherlands; Ph.: +31 30 6944651; Fax: +31 30 6957952; e-mail: Voorrips@voeding.tno.nl; ${ }^{2}$ Department of \\ Epidemiology, Maastricht University, Maastricht, The Netherlands (*Author for correspondence)
}

Received 14 September 1998; accepted in revised form 23 September 1999

Key words: cohort study, fruit, lung cancer, vegetables.

\begin{abstract}
Objective: The purpose was to study the association between vegetable and fruit consumption and lung cancer incidence using 1074 cases after 6.3 years of follow-up in the Netherlands Cohort Study.

Methods: Dietary intake was assessed using a 150-item food-frequency questionnaire. Multivariate models were used including age, sex, family history of lung cancer, highest educational level attained, and smoking history.

Results: Statistically significant inverse associations were found with total vegetables and most vegetable groups. Rate ratios (RRs) based on consumption frequency showed the strongest effect of vegetables from the Brassica group (RR 0.5, 95\% confidence interval $(95 \% \mathrm{CI}) \quad 0.3-0.9$, for consumption $\geq 3$ times per week versus $\leq$ once a month). RR of highest versus lowest quintile of total vegetable consumption was 0.7 (95\% CI $0.5-1.0$, $p$-trend 0.001). Statistically significant inverse associations were found for all fruits listed in the questionnaire. RRs for quintiles of total fruit intake were 1.0, 0.7, 0.6, 0.6 and 0.8 respectively ( $p$-trend $<0.0001$ ). Protective effects of fruits and vegetables were stronger in current than in former smokers, and weaker for adenocarcinomas than for other types of tumors.

Conclusions: Inverse associations with lung cancer are found for both vegetable and fruit intake, but no specific type of vegetable or fruit seems to be particularly responsible.
\end{abstract}

\section{Introduction}

In several reviews of epidemiologic studies, it is concluded that a high consumption of vegetables and fruits protects against cancer of a variety of anatomical sites, with the association being most marked for cancers of the alimentary and respiratory tracts [1-4]. With respect to lung cancer, especially the consumption of green leafy vegetables and carrots (both rich sources of carotenoids) appears to be inversely associated with the risk of this type of cancer.

Though most evidence of a protective effect of vegetable and fruit intake on lung cancer risk comes from case-control studies, this association has also been investigated in some cohort studies. In these cohort studies, inverse associations between vegetable consumption and lung cancer risk were found for all vegetables [5-9]; for yellow and red vegetables [5]; for green vegetables [5]; for dark green vegetables [8]; for green leafy vegetables [9]; for green salads [10, 11]; for green-yellow vegetables [12]; for yellow vegetables [8, 13]; for cruciferous vegetables [14]; for cabbage, rutabagas, carrots, cauliflower, lettuce and tomatoes [6]; and for high $\beta$-carotene vegetables, high vitamin $\mathrm{C}$ vegetables, carrots and broccoli [9], though many of the associations were not significant at the $5 \%$ level. In the Iowa Women's Health Study, lung cancer risk was approximately halved in the uppermost quartile of consumption of vegetables and fruit together [9]. Approximately the same risk reduction for the combination of vegetables and fruit was found for men and women in the NHANES I Epidemiologic Followup Study (NHEFS) [15]. For fruit, (not always statistically significant) inverse associations with lung cancer risk were 
found for all fruits [7-11, 14, 16]; for fruits and berries [5]; for citrus fruit [11, 16]; for oranges [14]; and dried fruit, canned or frozen fruit, and fresh winter fruit [11].

The cohort studies were conducted in very different parts of the world, i.e. Finland, Japan, the Netherlands, Norway, and the United States of America. The various geographical regions with their different dietary habits, traditional diets or smoking habits may account for the differences that were found in the associations between vegetable or fruit intake and lung cancer risk. Many of the studies mentioned above were performed in either men or women, and did not always include separate analyses for different smoking strata or tumor types. The Netherlands Cohort Study (NLCS) with 6.3 years of follow-up and more than a thousand incident lung cancer cases available provided the opportunity to study prospectively the detailed relationships between vegetable and fruit consumption and lung cancer incidence for men and women consuming a Dutch diet. Analyses could be performed separately for never, former and current smokers, and for cases with different types of tumors. From a biologic viewpoint, it is not yet clear whether the total amount of consumed vegetables (and fruits) is relevant for the possible protection against cancer or only the consumption frequency. In this study data are available on the consumption frequency of specific vegetables, but also on the estimated individual serving size of vegetables. We will therefore present data on the total amount as well as consumption frequency of vegetables in relation to lung cancer risk.

As the association between consumption of Allium vegetables and lung carcinoma risk has already been examined in the NLCS [17], analyses with these specific vegetables were not included in the present paper.

\section{Materials and methods}

\section{Subjects}

The Netherlands Cohort Study on diet and cancer is a prospective cohort study which started in September 1986. The study design has been reported in detail elsewhere [18]. The cohort included 62,573 women and 58,279 men aged 55-69 years at the beginning of the study. The study population originated from $204 \mathrm{mu}-$ nicipalities with computerized population registries.

\section{Data collection}

At baseline the cohort members completed a mailed, selfadministered questionnaire on dietary habits, lifestyle, smoking, personal and family history of cancer, and demographic data. The dietary section of the questionnaire was a 150 -item semi-quantitative food-frequency questionnaire which was validated against a 9-day diet record [19]. Spearman's correlation coefficients were 0.4 and 0.6 for total vegetable and fruit consumption respectively. The questionnaire concentrated on the habitual consumption of foods and beverages during the year preceding the start of the study. With regard to vegetable consumption, participants were asked to report their frequency of consumption of a number of vegetables, both in summer and in winter. They could choose one of six categories, ranging from "never or less than once per month" to "three to seven times per week". Usual serving sizes were asked for string beans and cooked endive only, the mean of which served as an indicator for serving sizes of all cooked vegetables. This procedure was chosen because in a pilot study it was shown that serving sizes of different types of cooked vegetables were correlated, although not strongly, within subjects. To derive an individual serving size for each type of vegetable the indicator serving size was multiplied with a type-specific factor calculated from the same pilot study data as the ratio of the means of the specific to the indicator serving sizes. For tomatoes and sweet peppers, consumption was asked in pieces per week and month respectively, during summer and winter. With regard to fruit consumption, frequencies varying from "never or less than once a month" to "six or seven times per week" and amounts consumed could be reported for mandarins, oranges, grapefruits, grapes, bananas, apples/pears and strawberries. Using standard portion sizes, these frequencies and amounts have been converted to consumption in grams per day. The choice of items for inclusion in the questionnaire was such that it covered almost all vegetables and fruits eaten regularly, with the exception of chicory, red cabbage and cucumber. An open-ended question on other foods eaten on a regular basis was also included. Participants could write down how many times per week they ate such a food and how much they were used eating on each occasion.

The method of record linkage to obtain information on cancer incidence has been described previously [20]. In short, follow-up for incident cancer has been established by computerized record linkage with all regional cancer registries in the Netherlands and with PALGA, a national database of pathology reports. After 6.3 years of follow-up, i.e. from September 1986 to December 1992, 1423 lung cancer cases were identified.

\section{Data analysis}

The case-cohort approach is used for data analysis [21]. This means that cases are enumerated for the entire 
cohort, while the person-years at risk of the entire cohort are estimated using a random subcohort sample. After baseline exposure measurement a subcohort of 1812 women and 1688 men was randomly sampled from the cohort and has been followed up biennially for vital status information. No subcohort members were lost to follow-up during the 6.3 years of follow-up.

After exclusion of cases who reported prevalent cancer other than skin cancer at baseline, incident cases without microscopically confirmed cancer, cases with lung cancer other than carcinoma (sarcoma, lymphoma, unspecified morphology) and cases with in-situ lung carcinoma, 1202 incident lung cancer cases were available for analyses. From the subcohort, prevalent cancer cases other than skin cancer were also excluded, leaving 1716 women and 1630 men.

Subjects with incomplete or inconsistent dietary data were also excluded from analyses [19]. In order to check the quality of the responses on the several vegetable questions, a specific error index was computed. When the error index exceeded a certain value, i.e. more than three errors, subjects were excluded from analyses on vegetable consumption. Finally, a total of 1010 lung cancer cases and 2953 subcohort members remained for the analysis of vegetable data and 1074 lung cancer cases and 3123 subcohort members for fruit data.

As the number of female lung cancer cases was relatively small (125 for vegetable analyses, 135 for fruit analyses), it was decided to perform most analyses with data pooled for men and women, with adjustment for sex in the model.

Analyses were performed on the overall consumption of vegetables and fruits, total vegetable consumption, total fruit consumption, individual vegetables and fruits as listed in the questionnaire, and several vegetable and fruit groups (raw vegetables, cooked vegetables, legumes, brassicas, cooked and raw leafy vegetables, and citrus fruit). To assess the effects of total amount of vegetable consumption versus frequency of vegetable consumption, we conducted both analyses for the major vegetable groups.

For the analyses with amount of vegetables or fruit, subjects were classified into quintiles, tertiles, or categories of vegetable or fruit consumption (g/day), depending on the distribution in the subcohort. For the analyses of vegetable groups based on consumption frequency, for some vegetables, frequencies had to be collapsed because of too few subjects.

Rate ratios (RRs) of lung cancer and their 95\% confidence intervals $(95 \% \mathrm{CI})$ were computed, using the GLIM statistical package [22]. Exponentially distributed survival times were assumed in the follow-up period. Since standard software was not available for case- cohort analysis, specific macros were developed to account for the additional variance introduced by sampling from the cohort instead of using the entire cohort [23]. Age, sex, highest level of education, family history of lung cancer, current cigarette smoking (yes/ no), number of cigarettes per day and years of smoking cigarettes were considered as potential confounders for which the rate ratios were adjusted. In additional multivariate analyses, the rate ratios were also adjusted for the consumption of total vegetables or fruits. Rate ratio estimates for the mean daily quantity of specific vegetables consumed were calculated for continuous variables (g/day) and expressed as increments of $25 \mathrm{~g} /$ day. This increment corresponds to a consumption frequency of approximately once per week for a cooked vegetable. The independent contribution of each specific vegetable was assessed by an analysis in which all vegetables were included in the model simultaneously. Tests for trend in the rate ratios were based on two-sided likelihood ratio tests. Rate ratios for quintiles of vegetable and fruit intake were also computed separately in never smokers, former smokers and current smokers. For the same variables, subgroup analyses were performed after stratification by histologic type of lung cancer. Lung cancer cases were classified into Kreyberg group I tumors (squamous cell, large cell, and small cell carcinoma: $72 \%$ ) and Kreyberg group II tumors (adenocarcinoma: 21\%) [24]. As distribution of histologic types differs strongly between sexes, these analyses were performed separately for men and women. As the number of women was relatively small, tertiles instead of quintiles were used for analyses on vegetable and fruit consumption.

\section{Results}

Table 1 shows the mean daily consumption of vegetables and fruit in lung cancer cases and subcohort members for men and women separately. In general, both vegetable and fruit intake was higher in women than in men. Fruit consumption was higher in subcohort members than in cases. Vegetable consumption also was higher in the subcohort, but only for men.

Mean daily consumption of vegetables and fruits was calculated for categories of the most important potential confounders of the association between lung cancer risk and vegetable or fruit consumption (e.g. age, smoking status, education, and family history of lung cancer). Fruit consumption was higher in the higher age categories, mean daily intakes being 171, 176 and $182 \mathrm{~g}$ for the consecutive 5-year intervals (though differences were not statistically significant (NS)). For vegetable 
Table 1. Daily vegetable and fruit consumption (in grams) in male and female lung cancer cases and subcohort members (mean (standard deviation (SD)): Netherlands Cohort Study 1986-1992

\begin{tabular}{|c|c|c|c|c|}
\hline \multirow[t]{2}{*}{ Vegetable consumption } & \multicolumn{2}{|l|}{ Men } & \multicolumn{2}{|l|}{ Women } \\
\hline & $\begin{array}{l}\text { Cases } \\
(n=885)\end{array}$ & $\begin{array}{l}\text { Subcohort } \\
(n=1456)\end{array}$ & $\begin{array}{l}\text { Cases } \\
(n=125)\end{array}$ & $\begin{array}{l}\text { Subcohort } \\
(n=1497)\end{array}$ \\
\hline Total vegetables ${ }^{1}$ & $176.5(71.1)$ & $187.1(76.3)$ & $194.3(78.2)$ & $191.0(74.5)$ \\
\hline Cooked vegetables & $144.1(59.2)$ & $150.8(63.1)$ & $154.1(66.5)$ & $149.5(59.3)$ \\
\hline Raw vegetables & $32.3(27.2)$ & $36.2(29.0)$ & $40.1(31.7)$ & $41.5(29.8)$ \\
\hline Brassicas & $31.1(19.5)$ & $32.7(20.3)$ & $32.4(21.3)$ & $31.6(20.0)$ \\
\hline Brussels sprouts & $7.4(6.9)$ & $7.7(6.7)$ & $8.5(6.6)$ & $7.7(7.4)$ \\
\hline Cauliflower & $13.5(10.7)$ & $14.6(11.1)$ & $14.9(11.7)$ & $13.9(10.5)$ \\
\hline Cabbage (white/green) & $7.0(7.9)$ & $7.2(8.2)$ & $5.6(8.1)$ & $6.9(8.0)$ \\
\hline Kale & $3.2(3.3)$ & $3.3(3.4)$ & $3.4(3.6)$ & $3.2(3.4)$ \\
\hline Legumes $^{2}$ & $33.7(22.2)$ & $34.7(23.0)$ & $29.7(21.4)$ & $30.7(20.7)$ \\
\hline String beans & $19.8(15.4)$ & $20.5(15.3)$ & $17.9(13.3)$ & $19.5(14.7)$ \\
\hline Broad beans & $4.8(7.2)$ & $4.7(7.2)$ & $4.4(6.4)$ & $4.3(6.6)$ \\
\hline Leafy vegetables, cooked & $20.3(15.3)$ & $21.6(16.0)$ & $22.4(18.9)$ & $21.3(14.9)$ \\
\hline Spinach & $9.3(8.7)$ & $9.6(8.9)$ & $10.0(9.3)$ & $9.4(8.3)$ \\
\hline Endive & $10.9(10.0)$ & $12.0(10.8)$ & $12.4(14.2)$ & $11.8(10.2)$ \\
\hline Leafy vegetables, raw & $8.3(7.7)$ & $9.9(9.2)$ & $10.4(10.8)$ & $10.1(8.4)$ \\
\hline Endive & $1.9(3.7)$ & $2.4(4.9)$ & $2.6(5.1)$ & $2.5(4.3)$ \\
\hline Lettuce & $6.4(6.2)$ & $7.6(6.7)$ & $7.9(8.4)$ & $7.6(6.6)$ \\
\hline \multicolumn{5}{|l|}{ Other vegetables } \\
\hline Carrots, cooked & $8.2(7.7)$ & $9.0(8.9)$ & $8.1(8.2)$ & $8.9(8.6)$ \\
\hline Carrots, raw & $1.2(4.6)$ & $2.1(7.8)$ & $2.5(7.6)$ & $3.5(9.4)$ \\
\hline Sweet peppers & $2.3(4.0)$ & $2.5(4.0)$ & $3.7(6.7)$ & $3.3(4.9)$ \\
\hline Sauerkraut & $5.7(5.7)$ & $5.9(5.5)$ & $6.6(5.9)$ & $5.7(4.9)$ \\
\hline Tomatoes & $18.5(21.1)$ & $19.5(20.0)$ & $23.7(20.8)$ & $23.5(20.3)$ \\
\hline Beetroot & $7.1(7.4)$ & $7.7(8.7)$ & $8.6(8.8)$ & $8.1(7.7)$ \\
\hline Mushrooms & $2.7(3.8)$ & $3.2(3.9)$ & $3.9(4.9)$ & $3.7(4.4)$ \\
\hline Gherkins & $1.7(5.6)$ & $1.9(8.1)$ & $1.5(4.7$ & $1.8(6.6)$ \\
\hline Rhubarb & $1.9(4.6)$ & $2.2(5.7)$ & $1.9(4.6)$ & $2.4(5.4)$ \\
\hline Fruit consumption & $\begin{array}{l}\text { Cases } \\
(n=939)\end{array}$ & $\begin{array}{l}\text { Subcohort } \\
(n=1525)\end{array}$ & $\begin{array}{l}\text { Cases } \\
(n=135)\end{array}$ & $\begin{array}{l}\text { Subcohort } \\
(n=1598)\end{array}$ \\
\hline Total fruit $^{1}$ & $134.9(112.6)$ & $154.4(111.8)$ & $175.4(137.9)$ & $196.1(118.9)$ \\
\hline Mandarins & $3.3(7.2)$ & $3.8(7.2)$ & $4.8(8.6)$ & $5.5(8.9)$ \\
\hline Oranges and fresh orange juice & $37.3(50.3)$ & $40.6(51.1)$ & $58.5(72.2)$ & $55.9(55.8)$ \\
\hline Grapefruits and fresh grapefruit juice & $5.9(20.5)$ & $6.6(21.7)$ & $10.4(24.4)$ & $11.4(26.3)$ \\
\hline Grapes & $3.5(8.3)$ & $3.9(8.5)$ & $5.9(8.9)$ & $5.0(9.7)$ \\
\hline Bananas & $11.9(27.6)$ & $12.9(25.0)$ & $13.4(25.9)$ & $12.9(26.8)$ \\
\hline Apples, pears & $55.3(71.1)$ & $67.4(74.6)$ & $64.1(81.1)$ & $84.2(82.0)$ \\
\hline Strawberries & $6.1(7.8)$ & $6.8(7.8)$ & $9.2(10.8)$ & $8.1(8.6)$ \\
\hline Citrus fruit ${ }^{1}$ & $57.6(71.3)$ & $64.8(69.8)$ & $87.6(86.7)$ & $88.2(73.2)$ \\
\hline Orange/grapefruit juice (processed) ${ }^{3}$ & $11.1(35.8)$ & $13.8(38.2)$ & $13.8(36.0)$ & $15.3(35.4)$ \\
\hline Other fruit juices ${ }^{3}$ & $7.0(28.4)$ & $7.8(28.7)$ & $11.8(51.0)$ & $12.8(34.2)$ \\
\hline
\end{tabular}

\footnotetext{
1 Including vegetables/fruits originating from an open ended question on frequently used products not mentioned in the questionnaire.

2 Also includes dried pulses.

3 Not included in total fruit.
}

consumption, no age effect was observed. Current smokers had lower intakes of vegetables (NS) and fruit (statistically significant, S) than former or never smokers. For current, former and never smokers mean daily consumption of vegetables was 184, 192 and $190 \mathrm{~g} /$ day, and fruit consumption 146, 173 and $201 \mathrm{~g}$ /day, respectively. A low educational level was generally associated with lower intakes of fruit and vegetables (NS). Subjects with a family history of lung cancer had slightly higher intakes of vegetables (NS) but not of fruits. The above-mentioned potential confounders have been accounted for in further analyses. The Spearman correlation coefficient between vegetable and fruit intake was 0.2 . 
Confounder-adjusted rate ratio estimates for quintiles or categories of consumption expressed in grams per day are presented in Table 2 for total vegetable and fruit intake, total vegetable intake, and intake of groups of vegetables. RRs showed statistically significant inverse trends for all vegetable groups, with the exception of raw leafy vegetables $(p=0.06)$. The RRs for the highest versus the lowest quintile of vegetable intake were 0.7 for total vegetable intake, intake of raw vegetables, legumes, brassicas and cooked leafy vegetables. For cooked vegetables and raw leafy vegetables, the RRs of the highest versus lowest category were 0.8 . After adjustment for total intake of vegetables the observed trends were no longer significant, although all associations remained inverse. Additional adjustment for fruit consumption did not alter the results (not presented).

Confounder-adjusted RRs for consumption frequency of different vegetable groups are presented in Table 3. Inverse associations were statistically significant for cooked and raw vegetables, brassicas, and raw leafy vegetables. The inverse association was strongest for vegetables of the brassica group, with a RR of 0.5 (95\% CI 0.3-0.9) for three (or more) times per week as compared to once (or less) per month. After adjustment was made for total frequency of vegetable intake, trends were no longer significant. The effect remained strongest in brassicas, with a RR of $0.6(95 \%$ CI $0.3-1.0)$ for three (or more) times per week versus once (or less) per month.

For specific vegetables, RRs are presented for increments in daily mean intake of $25 \mathrm{~g}$ /day (Table 4). RRs for all vegetables were below one, indicating a protective effect. However, the $95 \%$ confidence interval excluded one for cauliflower, cooked endive, and string beans only, whereas those for total vegetables, cooked vegetables, raw vegetables and lettuce were close to one. Sweet peppers were the only exception in showing a positive RR, but with very wide confidence limits due to low consumption. Table 4 also gives estimates for each vegetable after simultaneous adjustment for all other cooked or raw vegetables to assess their independent effects. Most RRs were closer to one, indicating that the inverse association of total vegetable intake and lung cancer is not exclusively attributable to a few vegetables.

In Table 5, RRs are presented for quintiles/categories of intake of fruit and fruit juices. After adjustment for confounders, trends for total fruit, citrus fruit and all separate fruits were (statistically significantly) negative. The strongest inverse association was found for oranges, with a RR of $0.6(95 \%$ CI $0.5-0.9)$ for the highest versus the lowest quintile of intake, followed by strawberries and mandarins. Citrus fruit as a group had a RR of 0.7 (95\% CI 0.5-0.9, highest versus lowest quintile). After adjustment for total fruit consumption, inverse trends remained statistically significant for citrus fruit, oranges, mandarins and bananas, but the inverse association with apples/pears disappeared. Additional adjustment for total vegetable intake did not change results at all (not presented).

In Table 6, the rate ratios are presented for combinations of vegetable and fruit consumption, both divided in tertiles of daily intake. For subjects in the lowest tertile of fruit consumption a significantly reduced risk was observed for persons with a higher vegetable intake. Similarly, for subjects in the lowest tertile of vegetable intake, fruit consumption reduced lung cancer risk, though not statistically significant. In both the highest vegetable and the highest fruit tertile additional high consumption of fruit or vegetables did not lead to a further decrease in relative risk for lung cancer.

Lung cancer remains a disease mainly caused by smoking. Only 57 cases occurred among never smokers as compared to 532 cases in current smokers and 321 among former smokers. In Table 7, the RRs for different quintiles of vegetable and fruit intake are presented for never smokers, current smokers and former smokers, respectively. Among never smokers, vegetable and fruit consumption were not inversely associated with lung cancer. Among former and current smokers inverse associations with statistically significant trends were found between total vegetable consumption and lung cancer risk. Inverse associations with cooked and raw vegetables showed statistically significant trends in current, but not in former smokers (data not shown). Likewise, the inverse association with fruit consumption only had a significant trend among current but not among former smokers. An inverse association with citrus fruit was found in current smokers but not in former smokers (data not shown).

As different histologic groups of carcinomas are suspected to have a different etiology, RRs of quintiles (men) or tertiles (women) of vegetable and fruit intake are shown for Kreyberg I and Kreyberg II carcinomas (Table 8). For Kreyberg I carcinomas a (statistically significant) negative trend was observed for vegetable intake among men but not in women. Fruit intake was protective in both sexes. For the less frequent Kreyberg II carcinomas only fruit consumption showed (statistically significant) inverse associations in men.

\section{Discussion}

The prospective Netherlands Cohort Study showed that both vegetable and fruit consumption were inversely associated with the risk of lung cancer. Vegetables from 
Table 2. Relative risks (RR) of lung cancer according to intake of combined vegetables and fruit, total vegetables and vegetable groups in gram/ day: Netherlands Cohort Study 1986-1992

\begin{tabular}{|c|c|c|c|c|c|c|}
\hline \multirow[t]{2}{*}{ Vegetable group } & \multicolumn{5}{|c|}{ Quintile/category of intake } & \multirow[t]{2}{*}{$p$-Trend } \\
\hline & $1(\text { low })^{1}$ & 2 & 3 & 4 & 5 (high) & \\
\hline \multicolumn{7}{|l|}{ All vegetables and fruits } \\
\hline Median intake (g/day) & 191 & 276 & 345 & 419 & 554 & \\
\hline Cases of lung cancer & 310 & 203 & 146 & 125 & 126 & \\
\hline Person-years & 3304 & 3443 & 3402 & 3431 & 3467 & \\
\hline $\mathrm{RR}^{2}$ & 1.0 & 0.8 & 0.6 & 0.5 & 0.7 & $<0.0001$ \\
\hline $95 \%$ Confidence interval & - & $0.6-1.1$ & $0.5-0.8$ & $0.4-0.70$ & $0.5-1.0$ & \\
\hline \multicolumn{7}{|l|}{ All vegetables } \\
\hline Median intake (g/day) & 103 & 145 & 178 & 217 & 286 & \\
\hline Cases of lung cancer & 206 & 214 & 175 & 169 & 146 & \\
\hline Person-years & 3308 & 3429 & 3428 & 3384 & 3498 & \\
\hline $\mathrm{RR}^{2}$ & 1.0 & 1.1 & 1.0 & 1.0 & 0.7 & 0.001 \\
\hline $95 \%$ Confidence interval & - & $0.8-1.5$ & $0.7-1.3$ & $0.7-1.3$ & $0.5-1.0$ & \\
\hline \multicolumn{7}{|l|}{ Cooked vegetables } \\
\hline Median intake $(\mathrm{g} /$ day $)$ & 79 & 114 & 142 & 174 & 231 & \\
\hline Cases of lung cancer & 187 & 205 & 179 & 166 & 173 & \\
\hline Person-years & 3288 & 3396 & 3440 & 3441 & 3481 & \\
\hline $\mathrm{RR}^{2}$ & 1.0 & 1.1 & 1.0 & 0.9 & 0.8 & 0.01 \\
\hline $95 \%$ Confidence interval & - & $0.8-1.4$ & $0.7-1.3$ & $0.7-1.2$ & $0.6-1.1$ & \\
\hline Vegetable-adjusted $\mathrm{RR}^{3}$ & 1.0 & 1.2 & 1.1 & 1.1 & 1.1 & 0.68 \\
\hline $95 \%$ Confidence interval & - & $0.9-1.6$ & $0.8-1.6$ & $0.7-1.6$ & $0.7-2.0$ & \\
\hline \multicolumn{7}{|l|}{ Raw vegetables } \\
\hline Median intake ( $\mathrm{g} /$ day) & 8 & 22 & 33 & 47 & 74 & \\
\hline Cases of lung cancer & 267 & 188 & 157 & 159 & 139 & \\
\hline Person-years & 3361 & 3411 & 3333 & 3470 & 3473 & \\
\hline $\mathrm{RR}^{2}$ & 1.0 & 0.8 & 0.9 & 0.9 & 0.7 & 0.04 \\
\hline $95 \%$ Confidence interval & - & $0.6-1.0$ & $0.7-1.2$ & $0.7-1.2$ & $0.6-1.0$ & \\
\hline Vegetable-adjusted $\mathrm{RR}^{3}$ & 1.0 & 0.8 & 0.9 & 1.0 & 0.9 & 0.70 \\
\hline $95 \%$ Confidence interval & - & $0.6-1.0$ & $0.7-1.2$ & $0.7-1.3$ & $0.6-1.2$ & \\
\hline \multicolumn{7}{|l|}{ Legumes } \\
\hline Median intake ( $\mathrm{g} /$ day) & 10 & 19 & 28 & 39 & 60 & \\
\hline Cases of lung cancer & 163 & 192 & 162 & 192 & 201 & \\
\hline Person-years & 3043 & 3494 & 3493 & 3581 & 3436 & \\
\hline $\mathrm{RR}^{2}$ & 1.0 & 1.0 & 0.7 & 0.8 & 0.7 & 0.002 \\
\hline $95 \%$ Confidence interval & - & $0.7-1.3$ & $0.5-0.9$ & $0.6-1.1$ & $0.5-1.0$ & \\
\hline Vegetable-adjusted $\mathrm{RR}^{3}$ & 1.0 & 1.0 & 0.7 & 0.9 & 0.8 & 0.07 \\
\hline $95 \%$ Confidence interval & - & $0.7-1.3$ & $0.5-1.0$ & $0.6-1.2$ & $0.6-1.2$ & \\
\hline \multicolumn{7}{|l|}{ Brassicas } \\
\hline Median intake (g/day) & 10 & 20 & 27 & 38 & 58 & \\
\hline Cases of lung cancer & 197 & 160 & 168 & 209 & 176 & \\
\hline Person-years & 3163 & 3280 & 3478 & 3653 & 3473 & \\
\hline $\mathrm{RR}^{2}$ & 1.0 & 0.8 & 0.7 & 0.8 & 0.7 & 0.009 \\
\hline $95 \%$ Confidence interval & - & $0.6-1.1$ & $0.6-1.0$ & $0.6-1.1$ & $0.5-1.0$ & \\
\hline Vegetable-adjusted $\mathrm{RR}^{3}$ & 1.0 & 0.8 & 0.8 & 0.9 & 0.8 & 0.36 \\
\hline $95 \%$ Confidence interval & - & $0.6-1.1$ & $0.6-1.1$ & $0.7-1.3$ & $0.6-1.2$ & \\
\hline \multicolumn{7}{|l|}{ Leafy vegetables, cooked } \\
\hline Median intake (g/day) & 4 & 12 & 19 & 26 & 41 & \\
\hline Cases of lung cancer & 211 & 180 & 157 & 197 & 165 & \\
\hline Person-years & 3344 & 3368 & 3102 & 3780 & 3454 & \\
\hline $\mathrm{RR}^{2}$ & 1.0 & 0.8 & 0.8 & 0.9 & 0.7 & 0.04 \\
\hline $95 \%$ Confidence interval & - & $0.6-1.0$ & $0.6-1.0$ & $0.7-1.2$ & $0.5-1.0$ & \\
\hline Vegetable-adjusted $\mathrm{RR}^{3}$ & 1.0 & 0.8 & 0.8 & 1.0 & 0.8 & 0.54 \\
\hline $95 \%$ Confidence interval & - & $0.6-1.1$ & $0.6-1.1$ & $0.8-1.4$ & $0.6-1.1$ & \\
\hline
\end{tabular}


Table 2. (Continued)

\begin{tabular}{|c|c|c|c|c|c|c|}
\hline \multirow[t]{2}{*}{ Vegetable group } & \multicolumn{5}{|c|}{ Quintile/category of intake } & \multirow[t]{2}{*}{$p$-Trend } \\
\hline & $1(\text { low })^{1}$ & 2 & 3 & 4 & 5 (high) & \\
\hline \multicolumn{7}{|l|}{ Leafy vegetables, raw } \\
\hline Median intake (g/day) & 3 & 8 & 18 & & & \multirow{5}{*}{0.06} \\
\hline Cases of lung cancer & 383 & 291 & 236 & & & \\
\hline Person-years & 6093 & 5640 & 5314 & & & \\
\hline $\mathrm{RR}^{2}$ & 1.0 & 0.9 & 0.9 & & & \\
\hline $95 \%$ Confidence interval & - & $0.8-1.2$ & $0.7-1.1$ & & & \\
\hline Vegetable-adjusted $\mathrm{RR}^{3}$ & 1.0 & 1.0 & 0.9 & & & \multirow[t]{2}{*}{0.37} \\
\hline $95 \%$ Confidence interval & - & $0.8-1.1$ & $0.8-1.1$ & & & \\
\hline
\end{tabular}

the brassica group showed the strongest association, but it appeared that all vegetables that were specified in the food-frequency questionnaire contributed to this inverse association. Citrus fruit turned out to be the main group responsible for the inverse association found with fruit consumption.

With 6.3 years of follow-up and more than a thousand lung cancer cases the power of the study is sufficiently large to exclude the overall observed results being caused by chance. The observation that all vegetables and fruits included in the study showed an inverse association with lung cancer supports this conclusion. The prospective nature of a cohort study together with completeness of follow-up, as has been achieved in this study, reduced the potential for selection bias to a minimum. Information bias, i.e. a change in (report of) dietary habits of lung cancer cases due to the disease, is also largely avoided in a prospective study because dietary habits were reported before the disease was diagnosed. A change in dietary habits of subjects with latent lung cancer at the time of completing the baseline questionnaire remains, however, a possibility, although this is much less likely than in subjects with, e.g. gastrointestinal cancer. Detailed analyses revealed that fruit consumption (but not vegetable consumption) of lung cancer cases diagnosed in the first year of follow-up was slightly lower than of cases diagnosed in later years. However, repeating analyses excluding first-year cases hardly affected our results.

A potentially more realistic threat to the interpretation of the observed inverse associations is residual confounding by risk factors for lung cancer that happen to be associated with vegetable or fruit consumption. The most important risk factor in this respect is cigarette smoking. Unhealthy habits, such as smoking and eating less vegetables and fruits, tend to cluster in the same subjects in most populations [25] and insufficient control of one factor will then confound the association between the other factor and lung cancer. In this way it might happen that an observed inverse association between vegetable consumption and lung cancer was due to residual confounding by smoking. Evidence of an association between smoking and vegetable consumption was also present in the NLCS, although not very strong and not very consistent. Current smokers had lower intakes of fruit and slightly lower intakes of vegetables than former or never smokers. We also made an attempt to model cigarette smoking habits such that they best explained lung cancer. This resulted in a model including: number of years smoked, habitual number of cigarettes smoked per day, both as continuous variables, and an indicator variable for current smoking. When we added the smoking variables to an age and sex-adjusted model, the RR estimate for total vegetables and lung cancer changed only slightly (data not shown). We therefore believe that the inverse association observed between vegetable or fruit consumption and lung cancer was not entirely due to residual confounding by smoking, although we cannot exclude some influence.

As alcohol consumption is sometimes associated with increased lung cancer risk [26, 27] we repeated analyses including alcohol in the model, but this did not alter the associations found. Also, adjustment for energy intake and body mass index did not affect results (data not shown). Apart from other confounders that were controlled for in the analysis (age, sex, education, and family history of lung cancer), unmeasured or unknown factors may have caused some confounding, but it is unlikely that such factors explain most of the 


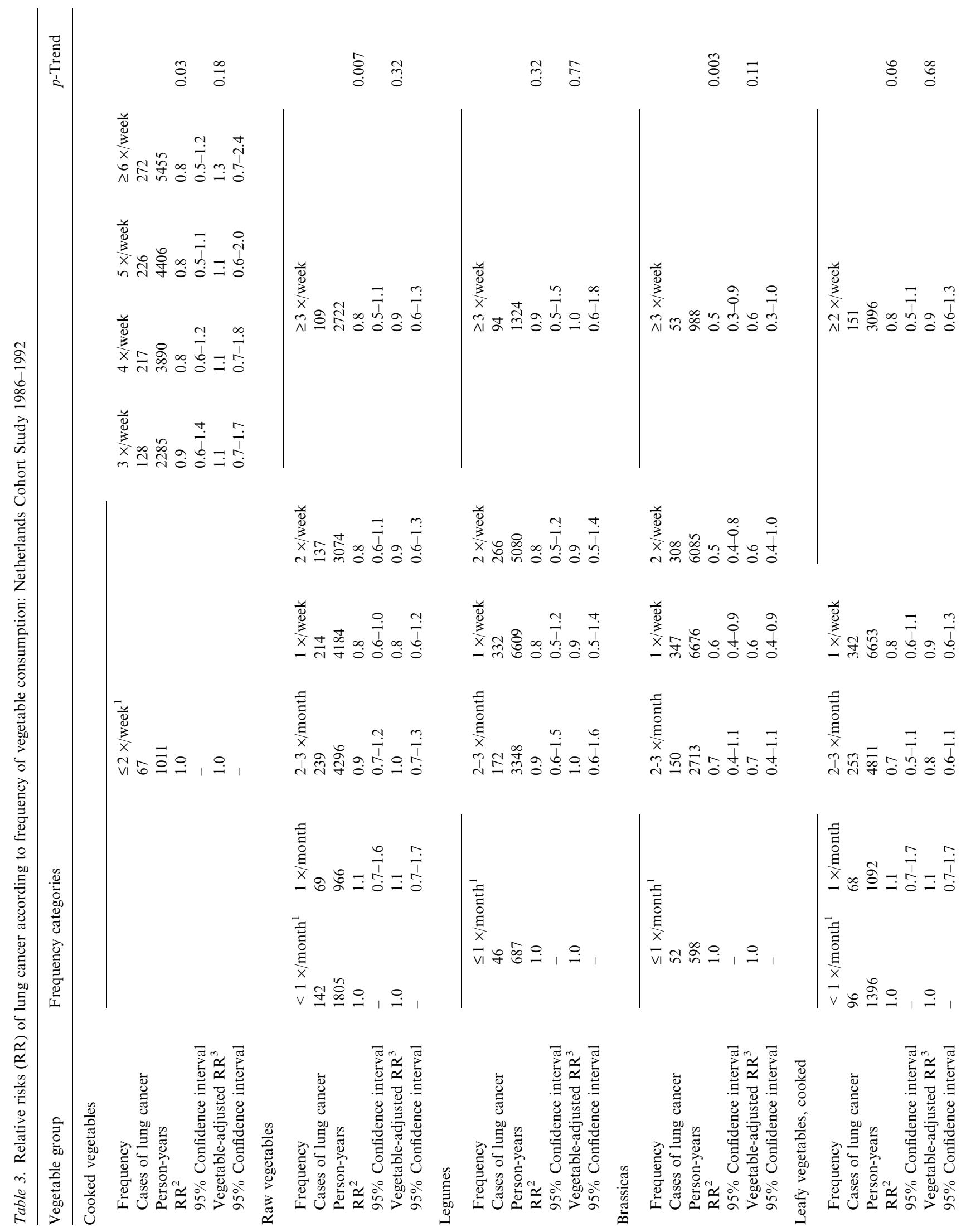




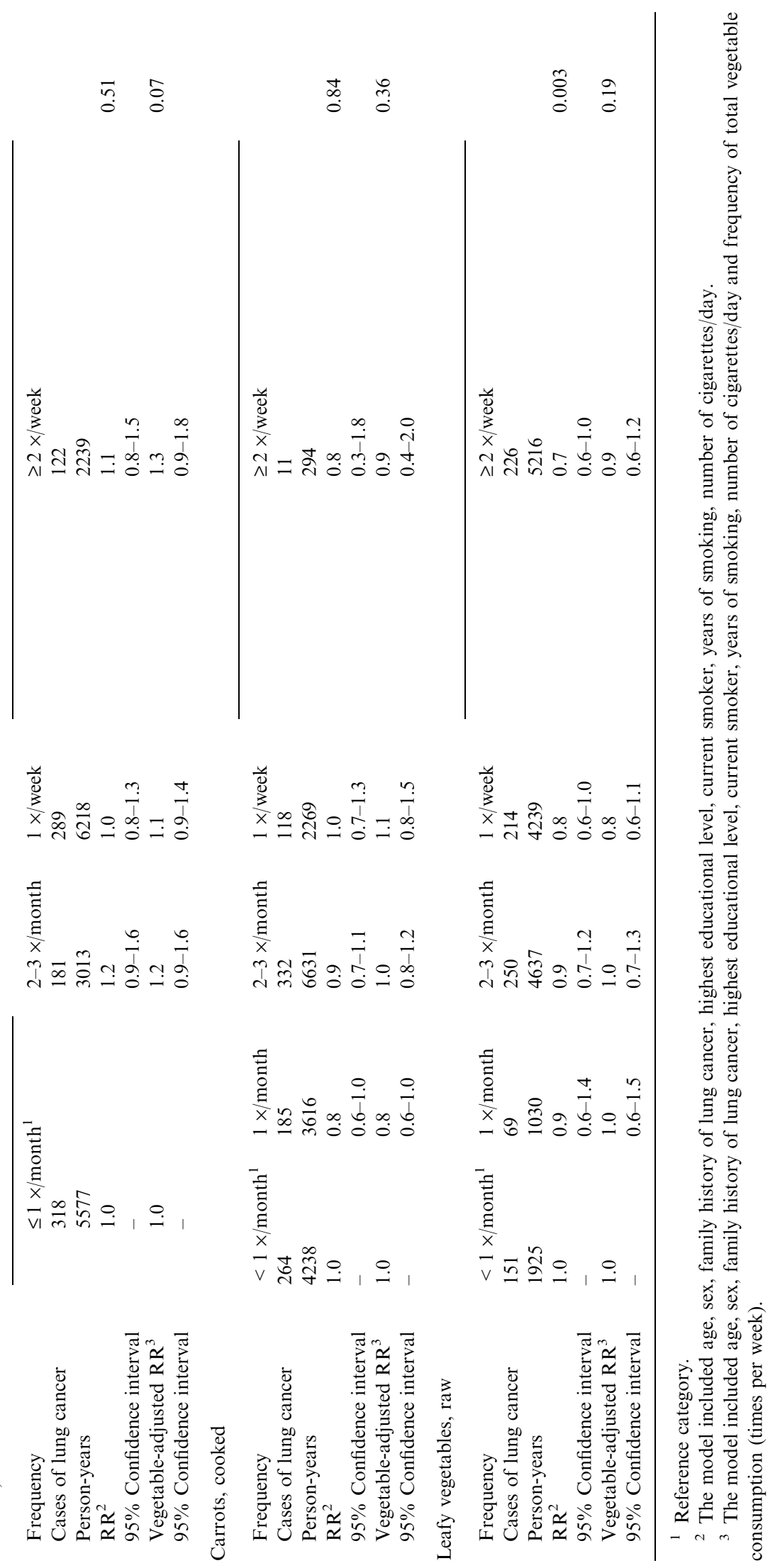


Table 4. Relative risks (RR) and 95\% confidence intervals (95\% CI) for continuous estimates of vegetable intake in relation to lung cancer incidence: Netherlands Cohort Study 1986-1992

\begin{tabular}{|c|c|c|c|c|c|}
\hline Vegetable & $\begin{array}{l}\text { Mean intake } \\
\text { subcohort } \\
\text { (g/day) }\end{array}$ & $\begin{array}{l}\mathrm{RR}^{1} \\
\text { per } \\
25 \mathrm{~g}\end{array}$ & $95 \% \mathrm{CI}$ & $\begin{array}{l}\mathrm{RR}^{2} \\
\text { adjusted } \\
\text { per } 25 \mathrm{~g}\end{array}$ & $95 \% \mathrm{CI}$ \\
\hline Total vegetables & 189.7 & 1.0 & $0.9-1.0$ & - & - \\
\hline Cooked vegetables & 150.8 & 1.0 & $0.9-1.0$ & - & - \\
\hline Brussels sprouts & 7.7 & 0.8 & $0.6-1.2$ & 1.0 & $0.7-1.4$ \\
\hline Cauliflower & 14.2 & 0.7 & $0.6-0.9$ & 0.8 & $0.6-1.0$ \\
\hline Cabbage & 7.0 & 0.9 & $0.6-1.1$ & 0.9 & $0.7-1.3$ \\
\hline Spinach & 9.5 & 1.0 & $0.8-1.3$ & 1.2 & $0.9-1.6$ \\
\hline Endive, cooked & 11.9 & 0.8 & $0.6-1.0$ & 0.8 & $0.6-1.0$ \\
\hline Beetroot & 7.9 & 0.9 & $0.7-1.2$ & 1.0 & $0.7-1.4$ \\
\hline String beans & 20.0 & 0.8 & $0.7-1.0$ & 0.9 & $0.7-1.0$ \\
\hline Broad beans & 4.5 & 0.9 & $0.7-1.2$ & 1.0 & $0.7-1.4$ \\
\hline Kale & 3.3 & 0.9 & $0.4-1.7$ & 0.9 & $0.4-1.9$ \\
\hline Carrots, cooked & 8.9 & 0.9 & $0.7-1.2$ & 1.1 & $0.8-1.5$ \\
\hline Sweet peppers & 2.9 & 1.3 & $0.7-2.2$ & 1.6 & $0.9-3.0$ \\
\hline Sauerkraut & 5.8 & 0.9 & $0.6-1.4$ & 1.2 & $0.7-1.9$ \\
\hline Rhubarb & 2.3 & 0.8 & $0.5-1.2$ & 0.8 & $0.5-1.2$ \\
\hline Mushrooms & 3.5 & 0.7 & $0.4-1.3$ & 0.6 & $0.3-1.1$ \\
\hline Gherkins & 1.9 & 0.8 & $0.6-1.1$ & 0.8 & $0.6-1.1$ \\
\hline Raw vegetables & 38.9 & 0.9 & $0.9-1.0$ & - & - \\
\hline Endive & 2.4 & 0.8 & $0.5-1.3$ & 0.8 & $0.5-1.4$ \\
\hline Carrots & 2.8 & 1.0 & $0.7-1.3$ & 1.0 & $0.8-1.4$ \\
\hline Lettuce & 7.6 & 0.7 & $0.5-1.0$ & 0.7 & $0.5-1.0$ \\
\hline Tomatoes & 21.5 & 1.0 & $0.9-1.1$ & 1.0 & $0.9-1.1$ \\
\hline
\end{tabular}

1 Adjusted for age, sex, current smoker, years of smoking cigarettes, habitual number of cigarettes per day, highest educational level, family history of lung cancer.

2 Adjusted for age, sex, current smoker, years of smoking cigarettes, habitual number of cigarettes per day, highest educational level, family history of lung cancer and the other vegetables of the cooked vegetable group and the raw vegetable group respectively.

association between vegetable or fruit consumption and lung cancer.

Could the assessment of vegetable or fruit consumption itself have biased the results obtained? Vegetables are generally considered as food items that are not very easy to assess in food-frequency questionnaires (as well as in other methods of dietary assessment), particularly if portion sizes have to be estimated. In the NLCS validation study, the correlation coefficient for total vegetable consumption was 0.4 [19], which is quite low, but comparable to the figure reported for many other prospective studies [28, 29]. One of the reasons for the low correlation may be the relative lack of true contrast in the frequency of vegetable consumption in a population such as the Dutch, because people are accustomed to a diet including one hot meal per day, which almost always includes vegetables. A consequence of a relatively large measurement error, resulting in an attenuation of the estimated RR, is underestimation of the inverse association between total vegetable consumption and lung cancer. Due to individual preferences, contrast in consumption frequency of many specific vegetables is much higher. It was not possible to assess validity for specific vegetables in the NLCS validation study, since 9 days of dietary record are not sufficient to estimate consumption frequency of specific vegetables.

To minimize the amount of uninformative data in addition to the general dietary exclusion criteria, we excluded subjects who appeared not to have understood how to fill in the questions on vegetable consumption, which occurred in the first part of the food-frequency questionnaire; those subjects were defined by an extreme score on the vegetable error index. Furthermore, to check the effect of excluding subjects with many food items left blank, as is part of our general dietary exclusion criteria, we recalculated our data with a very stringent selection excluding all subjects with more than five blanks. However, the inverse relations found turned out to be even stronger.

In the case of vegetable consumption we reported results for frequency of consumption as well as for categories of mean daily intake in grams, because it is not obvious from a biological point of view which parameter is most relevant for prevention of cancer. Furthermore, serving sizes are difficult to assess and may add more noise to the assessment of vegetable consumption than frequency alone. We conducted a validation of serving sizes of specific vegetables with the data from the NLCS validation study, and found correlation coefficients of about 0.25 for most vegetables, indicating that inclusion of serving size in the assessment of vegetable consumption adds information [30]. The results of the present analysis appeared to be comparable for both frequency of consumption and mean daily intake in grams. For cooked vegetables we used both frequency of consumption and individual serving size in the same model. Consumption frequency showed to have the most important effect, whereas individual serving size had only a minor contribution.

The association with lung cancer risk differed between groups of vegetables. In separate analyses of specified vegetables the inverse association was stronger for some, i.e. cauliflower, endive, string beans, and lettuce, than for others. This can be explained in part by their popularity among participants, which has resulted in large contrasts in consumption frequencies of these vegetables in the population. Nevertheless, carrots, which appeared to have a distribution of consumption frequencies comparable to that of cauliflower, did not show such a strong inverse association. Apart from sampling variation we do not have an obvious biological explanation for the relatively strong associations of the vegetables 
Table 5. Relative risks (RR) of lung cancer according to intake of fruit or fruit juice: Netherlands Cohort Study 1986-1992

\begin{tabular}{|c|c|c|c|c|c|c|}
\hline \multirow[t]{2}{*}{ Fruit group } & \multicolumn{5}{|c|}{ Quintile/category of intake } & \multirow[t]{2}{*}{$p$-Trend } \\
\hline & 1 (low) ${ }^{1}$ & 2 & 3 & 4 & 5 (high) & \\
\hline \multicolumn{7}{|l|}{ Total fruit } \\
\hline Median intake ( $\mathrm{g} /$ day) & 46 & 109 & 157 & 216 & 325 & \\
\hline Cases of lung cancer & 356 & 190 & 145 & 135 & 137 & \\
\hline Person-years & 3539 & 3527 & 3653 & 3614 & 3690 & \\
\hline $\mathrm{RR}^{2}$ & 1.0 & 0.7 & 0.6 & 0.6 & 0.8 & $<0.0001$ \\
\hline $95 \%$ Confidence interval & - & $0.6-1.0$ & $0.5-0.8$ & $0.4-0.8$ & $0.6-1.1$ & \\
\hline \multicolumn{7}{|c|}{ Oranges and fresh orange juice } \\
\hline Median intake (g/day) & 0 & 12 & 32 & 83 & 167 & \\
\hline Cases of lung cancer & 322 & 210 & 132 & 186 & 113 & \\
\hline Person-years & 3640 & 4164 & 2915 & 4841 & 2464 & \\
\hline $\mathrm{RR}^{2}$ & 1.0 & 0.6 & 0.7 & 0.6 & 0.6 & $<0.0001$ \\
\hline $95 \%$ Confidence interval & - & $0.5-0.8$ & $0.5-0.9$ & $0.5-0.8$ & $0.5-0.9$ & \\
\hline Total fruit-adjusted $\mathrm{RR}^{3}$ & 1.0 & 0.6 & 0.7 & 0.7 & 0.8 & 0.007 \\
\hline $95 \%$ Confidence interval & - & $0.5-0.8$ & $0.5-0.9$ & $0.5-0.9$ & $0.5-1.1$ & \\
\hline \multicolumn{7}{|l|}{ Mandarins } \\
\hline Median intake (g/day) & 0 & 2 & 8 & & & \\
\hline Cases of lung cancer & 504 & 270 & 189 & & & \\
\hline Person-years & 7218 & 5633 & 5173 & & & \\
\hline $\mathrm{RR}^{2}$ & 1.0 & 0.9 & 0.7 & & & 0.0001 \\
\hline $95 \%$ Confidence interval & - & $0.7-1.1$ & $0.6-0.9$ & & & \\
\hline Total fruit-adjusted $\mathrm{RR}^{3}$ & 1.0 & 0.9 & 0.8 & & & 0.002 \\
\hline $95 \%$ Confidence interval & - & $0.7-1.1$ & $0.6-0.9$ & & & \\
\hline \multicolumn{7}{|c|}{ Grapefruits and fresh grapefruit juice } \\
\hline Median intake (g/day) & 0 & 16 & & & & \\
\hline Cases of lung cancer & 798 & 165 & & & & \\
\hline Person-years & 12815 & 5210 & & & & \\
\hline $\mathrm{RR}^{2}$ & 1.0 & 0.8 & & & & \\
\hline $95 \%$ Confidence interval & - & $0.6-1.0$ & & & & \\
\hline Total fruit-adjusted $\mathrm{RR}^{3}$ & 1.0 & 0.9 & & & & \\
\hline $95 \%$ Confidence interval & - & $0.7-1.1$ & & & & \\
\hline \multicolumn{7}{|l|}{ Citrus fruit } \\
\hline Median intake (g/day) & 3 & 28 & 62 & 100 & 175 & \\
\hline Cases of lung cancer & 336 & 195 & 172 & 108 & 152 & \\
\hline Person-years & 3533 & 3651 & 4053 & 3134 & 3653 & \\
\hline $\mathrm{RR}^{2}$ & 1.0 & 0.7 & 0.7 & 0.7 & 0.7 & $<0.0001$ \\
\hline $95 \%$ Confidence interval & - & $0.6-0.9$ & $0.5-0.9$ & $0.5-0.9$ & $0.5-0.9$ & \\
\hline Total fruit-adjusted $\mathrm{RR}^{3}$ & 1.0 & 0.7 & 0.7 & 0.7 & 0.8 & 0.01 \\
\hline $95 \%$ Confidence interval & - & $0.6-1.0$ & $0.5-0.9$ & $0.5-1.0$ & $0.6-1.1$ & \\
\hline \multicolumn{7}{|l|}{ Apples and pears } \\
\hline Median intake (g/day) & 0 & 45 & 80 & 116 & 232 & \\
\hline Cases of lung cancer & 364 & 271 & 105 & 144 & 79 & \\
\hline Person-years & 4110 & 4860 & 2789 & 4063 & 2202 & \\
\hline $\mathrm{RR}^{2}$ & 1.0 & 0.8 & 0.7 & 0.7 & 0.8 & 0.0003 \\
\hline $95 \%$ Confidence interval & - & $0.6-1.0$ & $0.6-1.0$ & $0.5-0.9$ & $0.6-1.1$ & \\
\hline Total fruit-adjusted $\mathrm{RR}^{3}$ & 1.0 & 0.8 & 0.8 & 0.8 & 1.1 & 0.20 \\
\hline $95 \%$ Confidence interval & - & $0.7-1.1$ & $0.6-1.2$ & $0.6-1.1$ & $0.7-1.7$ & \\
\hline \multicolumn{7}{|l|}{ Bananas } \\
\hline Median intake ( $\mathrm{g} /$ day) & 0 & 4 & 32 & & & \\
\hline Cases of lung cancer & 501 & 250 & 212 & & & \\
\hline Person-years & 8515 & 5163 & 4347 & & & \\
\hline $\mathrm{RR}^{2}$ & 1.0 & 0.9 & 0.8 & & & 0.003 \\
\hline $95 \%$ Confidence interval & - & $0.7-1.1$ & $0.6-1.0$ & & & \\
\hline Total fruit-adjusted $\mathrm{RR}^{3}$ & 1.0 & 0.9 & 0.8 & & & 0.03 \\
\hline $95 \%$ Confidence interval & - & $0.7-1.1$ & $0.7-1.1$ & & & \\
\hline
\end{tabular}


Table 5. (Continued)

\begin{tabular}{|c|c|c|c|c|c|c|}
\hline \multirow[t]{2}{*}{ Fruit group } & \multicolumn{5}{|c|}{ Quintile/category of intake } & \multirow[t]{2}{*}{$p$-Trend } \\
\hline & $1(\text { low })^{1}$ & 2 & 3 & 4 & 5 (high) & \\
\hline \multicolumn{7}{|l|}{ Strawberries } \\
\hline Median intake ( $\mathrm{g} /$ day) & 0 & 4 & 6 & 9 & 18 & \\
\hline Cases of lung cancer & 282 & 267 & 102 & 193 & 119 & \\
\hline Person-years & 4043 & 4847 & 2017 & 3956 & 3162 & \\
\hline $\mathrm{RR}^{2}$ & 1.0 & 0.8 & 0.9 & 1.0 & 0.7 & 0.02 \\
\hline $95 \%$ Confidence interval & - & $0.6-1.0$ & $0.7-1.3$ & $0.7-1.2$ & $0.5-0.9$ & \\
\hline Total fruit-adjusted $\mathrm{RR}^{3}$ & 1.0 & 0.8 & 0.9 & 1.0 & 0.7 & 0.15 \\
\hline $95 \%$ Confidence interval & - & $0.7-1.1$ & $0.7-1.3$ & $0.8-1.3$ & $0.5-1.0$ & \\
\hline \multicolumn{7}{|l|}{ Grapes } \\
\hline Median intake (g/day) & 0 & 2 & 9 & & & \\
\hline Cases of lung cancer & 441 & 293 & 229 & & & \\
\hline Person-years & 6841 & 5854 & 5330 & & & \\
\hline $\mathrm{RR}^{2}$ & 1.0 & 1.0 & 0.8 & & & 0.04 \\
\hline $95 \%$ Confidence interval & - & $0.8-1.2$ & $0.7-1.0$ & & & \\
\hline Total fruit-adjusted $\mathrm{RR}^{3}$ & 1.0 & 1.0 & 0.9 & & & 0.26 \\
\hline 95\% Confidence interval & - & $0.8-1.2$ & $0.7-1.1$ & & & \\
\hline \multicolumn{7}{|c|}{ Orange/grapefruit juice (processed) } \\
\hline Median intake (g/day) & 0 & 20 & & & & \\
\hline Cases of lung cancer & 711 & 252 & & & & \\
\hline Person-years & 11095 & 6930 & & & & \\
\hline $\mathrm{RR}^{2}$ & 1.0 & 0.9 & & & & 0.09 \\
\hline $95 \%$ Confidence interval & - & $0.7-1.1$ & & & & \\
\hline Total fruit-adjusted $\mathrm{RR}^{3}$ & 1.0 & 0.9 & & & & 0.06 \\
\hline $95 \%$ Confidence interval & - & $0.7-1.1$ & & & & \\
\hline \multicolumn{7}{|l|}{ Other fruit juices } \\
\hline Median intake (g/day) & 0 & 20 & & & & \\
\hline Cases of lung cancer & 801 & 162 & & & & \\
\hline Person-years & 13555 & 4469 & & & & \\
\hline $\mathrm{RR}^{2}$ & 1.0 & 0.9 & & & & 0.36 \\
\hline $95 \%$ Confidence interval & - & $0.7-1.2$ & & & & \\
\hline Total fruit-adjusted $\mathrm{RR}^{3}$ & 1.0 & 0.9 & & & & 0.40 \\
\hline $95 \%$ Confidence interval & - & $0.7-1.2$ & & & & \\
\hline
\end{tabular}

1 Reference category.

2 The model included age, sex, family history of lung cancer, highest educational level, current smoker, years of smoking, number of cigarettes/day.

${ }^{3}$ The model included age, sex, family history of lung cancer, highest educational level, current smoker, years of smoking, number of cigarettes/ day and total fruit intake (g/day).

mentioned. For example, cauliflower belongs to the Brassica genus, which contains possibly cancer-protective glucosinolates [31], but so do Brussels sprouts, cabbage and kale, which did not show strong inverse associations. The findings that most vegetables were inversely associated with lung cancer, and that simultaneous inclusion of all vegetables in the model increased the RRs, are more supportive of a general vegetable effect.

For fruit consumption, no separate analyses were made with respect to frequencies. Contrary to vegetables, which are eaten as part of the one hot meal per day in the Dutch diet, fruits can be consumed on several occasions. Our questionnaire data do not permit us to distinguish between one consumption of three manda- rins at the same time, or three mandarins eaten on different occasions during the day.

We did not observe any protective effect of vegetable consumption in never smokers, whereas Knekt et al. [5] on the contrary reported protective effects in nonsmokers but not in current smokers. However, in the study of Knekt et al. nonsmokers were defined as never smokers (six cases) plus former smokers (18 cases), and smoking history was not included in the analysis. Although the statistical power of our subgroup analysis of never smokers was too small to permit strong conclusions, the lack of an effect might be due to the fact that never smokers have not been exposed to the type of carcinogens in cigarette smoke that may be affected by vegetable 
Table 6. $\mathrm{RR}^{1}$ estimates ( $95 \%$ confidence intervals) for combinations of tertiles of vegetable and fruit consumption: Netherlands Cohort Study 1986-1992

\begin{tabular}{llll}
\hline Fruit consumption & \multicolumn{2}{l}{ Vegetable consumption } \\
\cline { 2 - 4 } & $\leq 150 \mathrm{~g} /$ day & $150-212 \mathrm{~g} /$ day & $\geq 212 \mathrm{~g} / \mathrm{day}$ \\
\hline$\leq 115 \mathrm{~g} /$ day & 1.0 & 1.2 & 0.7 \\
& & $(0.8-1.6)$ & $(0.5-0.9)$ \\
$115-203 \mathrm{~g} /$ day & 0.7 & 0.7 & 0.6 \\
& $(0.5-1.1)$ & $(0.5-1.0)$ & $(0.4-0.8)$ \\
$\geq 203 \mathrm{~g} /$ day & 0.7 & 0.5 & 0.8 \\
& $(0.5-1.1)$ & $(0.4-0.8)$ & $(0.5-1.1)$ \\
\hline
\end{tabular}

1 Adjusted for age, sex, current smoker, years of smoking cigarettes, number of cigarettes per day, highest educational level, and family history of lung cancer.

or fruit consumption [1]. The observation that the protective effect of vegetables and fruits is stronger in current than in former smokers agrees with this explanation. In the NHANES I Epidemiologic Followup Study cohort risk reduction by increased intake of vegetables and fruit was found also in current smokers and not among nonsmokers (never plus former smokers) [15]. In a recent study [32], it was found that antioxidant micronutrients protect against DNA damage by polycyclic aromatic hydrocarbons present in cigarette smoke, especially in smokers lacking the glutathione $S$-transferase M1 detoxification gene. The findings in never smokers do not imply that never smokers do not benefit from vegetable or fruit consumption, but only that their already low risk of lung cancer is not reduced further. In the Iowa Women's Health Study stronger inverse associations were found in former smokers than in current smokers [9]. The main difference with our study is that in the Iowa Study only women participated, whereas in the NLCS both sexes were present, but lung cancer cases were predominantly men. Analyzing the effect of vegetable consumption for different histologic types of cancer showed for men an inverse relationship with lung cancer in Kreyberg type I tumors (squamous cell, large cell, and small cell carcinoma) but not in Kreyberg type II tumors (adenocarcinomas). This has been observed by others [1], and might be due to the fact that adenocarcinomas are less strongly related to smoking. The weaker relationships in Kreyberg II tumors may partly be explained by the fact that in our study, as in most studies, Kreyberg I is the predominant histologic type. However, especially among men the number of adenocarcinomas (146 cases) is expected to be sufficient to show strong relationships with vegetable or fruit consumption. It is not clear why similar differences between cancer sites were not found in women.

What are the implications of the results observed? Lung cancer is a disease that is mainly caused by smoking cigarettes. For example, from data of the NLCS it can be calculated that a male, current smoker who smoked 25 cigarettes per day for 40 years has a risk of attracting lung cancer that is 18 times as high as that of a never smoker. By eating $286 \mathrm{~g}$ of vegetables (highest quintile) instead of $103 \mathrm{~g}$ (lowest quintile) daily, he may reduce his risk by $29 \%$.

Table 7. Rate ratios $^{1}$ (95\% confidence intervals) for vegetable intake and fruit intake ${ }^{2}$, among never smokers, current smokers and former smokers respectively: Netherlands Cohort Study 1986-1992

\begin{tabular}{|c|c|c|c|c|c|c|}
\hline & \multicolumn{2}{|c|}{ Never smokers ${ }^{3}$} & \multicolumn{2}{|c|}{ Former smokers $^{3}$} & \multicolumn{2}{|c|}{ Current smokers ${ }^{3}$} \\
\hline & $\mathrm{RR}$ & $p$-Trend & $\mathrm{RR}$ & $p$-Trend & $\mathrm{RR}$ & $p$-Trend \\
\hline \multicolumn{7}{|l|}{ All vegetables } \\
\hline Quintile $1^{4}$ & 1.0 & 0.06 & 1.0 & 0.03 & 1.0 & 0.003 \\
\hline Quintile 2 & $1.1(0.4-3.1)$ & & $1.1(0.7-1.8)$ & & $1.2(0.8-1.7)$ & \\
\hline Quintile 3 & $2.1(0.8-5.6)$ & & $1.1(0.7-1.8)$ & & $0.9(0.6-1.3)$ & \\
\hline Quintile 4 & $2.3(0.9-5.8)$ & & $0.9(0.6-1.5)$ & & $1.0(0.7-1.5)$ & \\
\hline Quintile 5 & $1.8(0.7-4.7)$ & & $0.7(0.4-1.1)$ & & $0.7(0.5-1.0)$ & \\
\hline \multicolumn{7}{|l|}{ All fruits } \\
\hline Quintile $1^{4}$ & 1.00 & 0.44 & 1.0 & 0.26 & 1.0 & $<0.0001$ \\
\hline Quintile 2 & $0.9(0.4-2.3)$ & & $0.6(0.4-1.0)$ & & $0.8(0.6-1.2)$ & \\
\hline Quintile 3 & $0.7(0.3-1.9)$ & & $0.6(0.4-0.9)$ & & $0.7(0.5-1.1)$ & \\
\hline Quintile 4 & $0.7(0.3-1.7)$ & & $0.7(0.4-1.1)$ & & $0.5(0.4-0.8)$ & \\
\hline Quintile 5 & $1.4(0.6-3.2)$ & & $0.8(0.5-1.3)$ & & $0.7(0.4-1.0)$ & \\
\hline
\end{tabular}

1 Adjusted for highest educational level, family history of lung cancer, age and sex. For current smokers and former smokers: also adjusted for years of smoking cigarettes and number of cigarettes per day.

2 Median intake per quintile/category given in Tables 3 and 6.

3 Vegetable/fruit consumption: never smokers 57/62 cases, former smokers 321/331 cases, current smokers 532/568 cases.

4 Reference category. 
Table 8. Rate ratios ${ }^{1}\left(95 \%\right.$ confidence intervals) for quintiles (men) or tertiles ${ }^{2}$ (women) of vegetable intake and fruit intake, stratified by histologic type of lung cancer: Netherlands Cohort Study 1986-1992

\begin{tabular}{|c|c|c|c|c|c|c|c|c|}
\hline & \multicolumn{4}{|l|}{ Men } & \multicolumn{4}{|l|}{ Women } \\
\hline & \multicolumn{2}{|l|}{ Kreyberg $\mathrm{I}^{4}$} & \multicolumn{2}{|l|}{ Kreyberg II ${ }^{5}$} & \multicolumn{2}{|l|}{ Kreyberg I ${ }^{4}$} & \multicolumn{2}{|l|}{ Kreyberg II ${ }^{5}$} \\
\hline & RR $(95 \%$ CI $)$ & $p$-Trend & RR $(95 \%$ CI $)$ & $p$-Trend & $\operatorname{RR}(95 \% \mathrm{CI})$ & $p$-Trend & RR $(95 \% \mathrm{CI})$ & $p$-Trend \\
\hline \multicolumn{9}{|l|}{ All vegetables ${ }^{6}$} \\
\hline Quintile/tertile $1^{3}$ & 1.0 & $<0.0001$ & 1.0 & 1.00 & 1.0 & 0.21 & 1.0 & 0.95 \\
\hline Quintile/tertile 2 & $1.1(0.8-1.6)$ & & $0.9(0.5-1.7)$ & & $1.0(0.5-2.1)$ & & $1.6(0.7-3.4)$ & \\
\hline Quintile/tertile 3 & $0.9(0.6-1.3)$ & & $1.3(0.7-2.2)$ & & $1.4(0.8-2.7)$ & & $1.0(0.5-2.3)$ & \\
\hline Quintile 4 & $0.9(0.6-1.3)$ & & $1.5(0.9-2.6)$ & & & & & \\
\hline Quintile 5 & $0.6(0.4-0.9)$ & & $0.8(0.4-1.4)$ & & & & & \\
\hline \multicolumn{9}{|l|}{ All fruits ${ }^{6}$} \\
\hline Quintile/tertile $1^{3}$ & 1.0 & 0.0001 & 1.0 & 0.02 & 1.0 & 0.03 & 1.0 & 0.68 \\
\hline Quintile/tertile 2 & $0.7(0.5-0.9)$ & & $0.6(0.4-1.0)$ & & $0.4(0.2-0.7)$ & & $1.0(0.5-2.2)$ & \\
\hline Quintile/tertile 3 & $0.6(0.5-0.9)$ & & $0.6(0.3-1.0)$ & & $0.6(0.3-1.1)$ & & $0.9(0.4-1.9)$ & \\
\hline Quintile 4 & $0.6(0.4-0.8)$ & & $0.4(0.3-0.8)$ & & & & & \\
\hline Quintile 5 & $0.7(0.5-1.1)$ & & $0.8(0.4-1.3)$ & & & & & \\
\hline
\end{tabular}

${ }^{1}$ Adjusted for current smoker, years of smoking cigarettes, number of cigarettes per day, highest educational level, family history of lung cancer, and age.

${ }^{2}$ Due to small numbers tertiles had to be used for stratified analyses in women.

${ }^{3}$ Reference category.

${ }^{4}$ Kreyberg I: squamous cell, large cell, and small cell carcinoma.

${ }^{5}$ Kreyberg II: adenocarcinoma.

${ }^{6}$ Vegetable/fruit consumption: men: Kreyberg I: 575/611 cases, Kreyberg II: 146/150 cases, women: Kreyberg I: 68/77 cases, Kreyberg II: $44 / 44$ cases.

In conclusion, it could be stated that inverse associations have been found between consumption of vegetables, fruits and lung cancer incidence, which are unlikely to be due to residual confounding of smoking. The summed total of vegetables and fruits appears to be more important than the contribution of specific vegetables or fruits.

\section{Acknowledgements}

The authors gratefully acknowledge the Regional Cancer Registries, the Dutch database of Pathology (PALGA), and the National Health Care Information Center for providing incidence data. We also thank Henny Brants, Sacha van de Crommert, Jolanda Nelissen and Willy van Dijk for their expert help. The study was financially supported by the Dutch Cancer Society, the Dutch Product Board for Horticulture, and Unilever Research Laboratories.

\section{References}

1. Steinmetz KA, Potter JD (1991) Vegetables, fruit, and cancer. I. Epidemiology. Cancer Causes Control 2: 325-357.
2. Steinmetz KA, Potter JD (1996) Vegetables, fruit, and cancer prevention: a review. J Am Diet Assoc 96: 1027-1039.

3. Block G, Patterson B, Subar A (1992) Fruit, vegetables, and cancer prevention: a review of the epidemiological evidence. Nutr Cancer 18: $1-29$.

4. Ziegler RG, Mayne ST, Swanson CA (1996) Nutrition and lung cancer. Cancer Causes Control 7: 157-177.

5. Knekt P, Jarvinen R, Seppänen R, et al. (1991) Dietary antioxidants and the risk of lung cancer. Am J Epidemiol 134: 471-479.

6. Kvåle G, Bjelke E, Gart JJ (1983) Dietary habits and lung cancer risk. Int J Cancer Inst 31: 397-405.

7. Ocké MC, Bueno de Mesquita HB, Feskens EJM, van Staveren WA, Kromhout D (1997) Repeated measurements of vegetables, fruits, $\beta$-carotene, and vitamins $\mathrm{C}$ and $\mathrm{E}$ in relation to lung cancer. Am J Epidemiol 145: 358-365.

8. Shibata A, Paganini-Hill A, Ross RK, Henderson BE (1992) Intake of vegetables, fruits, beta-carotene, vitamin $\mathrm{C}$ and vitamin supplements and cancer incidence among the elderly: a prospective study. Br J Cancer 66: 673-679.

9. Steinmetz KA, Potter JD, Folsom AR (1993) Vegetables, fruit, and lung cancer in the Iowa Women's Health Study. Cancer Res 53: 536-543.

10. Long-de W, Hammond C (1985) Lung cancer, fruit, green salad and vitamin pills. Chin Med J 98: 206-210.

11. Fraser GE, Beeson WL, Phillips RL (1991) Diet and lung cancer in California Seventh-day Adventists. Am J Epidemiol 133: 683693.

12. Hirayama T (1990) Contribution of a long-term prospective cohort study to the issue of nutrition and cancer with special reference to the role of alcohol drinking. Prog Clin Biol Res 346: 179-187. 
13. Shibata A, Paganini-Hill A, Ross RK, Yu MC, Henderson BE (1992) Dietary beta-carotene, cigarette smoking, and lung cancer in men. Cancer Causes Control 3: 207-214.

14. Chow WH, Schuman LM, McLaughin JK, et al. (1992) A cohort study of tobacco use, diet, occupation, and lung cancer mortality. Cancer Causes Control 3: 247-254.

15. Yong LC, Brown CC, Schatzkin A, et al. (1997) Intake of vitamins $\mathrm{E}, \mathrm{C}$, and $\mathrm{A}$ and risk of lung cancer - The NHANES I Epidemiologic Followup Study. Am J Epidemiol 146: 231-243.

16. Kromhout D (1987) Essential micronutrients in relation to carcinogenesis. Am J Clin Nutr 45: 1361-1367.

17. Dorant E, van den Brandt PA, Goldbohm RA (1994) A prospective cohort study on Allium vegetable consumption, garlic supplement use, and the risk of lung carcinoma in the Netherlands. Cancer Res 54: 6148-6153.

18. van den Brandt PA, Goldbohm RA, van't Veer P, Volovics A, Hermus RJJ, Sturmans F (1990) A large-scale prospective cohort study on diet and cancer in The Netherlands. J Clin Epidemiol 43: 285-295.

19. Goldbohm RA, van den Brandt PA, Brants HAM, et al. (1994) Validation of a dietary questionnaire used in a large-scale prospective cohort study on diet and cancer. Eur J Clin Nutr 48: $253-265$.

20. van den Brandt PA, Schouten LJ, Goldbohm RA, Dorant E, Hunen PMH (1990) Development of a record linkage protocol for use in the Dutch cancer registry for epidemiological research. Int $J$ Epidemiol 19: 553-558.

21. Self SG, Prentice RL (1988) Asymptotic distribution theory and efficiency results for case-cohort studies. Ann Stat 16: 64-81.

22. Baker RJ (1985) GLIM 3.77 Reference Manual. Oxford: Numerical Algorithms Group.
23. Volovics A, van den Brandt PA (1997) Methods for the analyses of case-cohort studies. Biomed J 2: 195-214.

24. Doll R, Hill AB, Kreyberg L (1957) The significance of cell type in relation to the aetiology of lung cancer. Br J Cancer 11: 43-48.

25. Morabia A, Wynder EL (1990) Dietary habits of smokers, people who never smoked, and exsmokers. Am J Clin Nutr 52: 933-937.

26. Potter JD, Sellers TA, Folsom AR, McGovern PG (1992) Alcohol, beer, and lung cancer in postmenopausal women. The Iowa Women's Health Study. Ann Epidemiol 2: 587-595.

27. Bandera EV, Freudenheim JL, Graham S, et al. (1992) Alcohol consumption and lung cancer in white males. Cancer Causes Control 3: 361-369.

28. Ocké MC, Bueno de Mesquita HB, Goddijn HE, et al. (1997) The Dutch EPIC food frequency questionnaire. I. Description of the questionnaire, and relative validity and reproducibility for food groups. Int J Epidemiol 26 (Suppl. 1): S37-S48.

29. Smith-Warner SA, Elmer PJ, Fosdick L, Tharp TM, Randall B (1997) Reliability and comparability of three dietary assessment methods for estimating fruit and vegetable intakes. Epidemiology 8: 196-201.

30. Verhoeven DTH, Goldbohm RA (1997) Validering van groentengegevens in de Nederlandse Cohortstudie naar voeding en kanker. TNO rapport V97.151/NLCS 97-02. TNO Voeding Zeist.

31. Verhoeven DTH, Verhagen H, Goldbohm RA, van den Brandt PA, van Poppel G (1997) A review of mechanisms underlying anticarcinogenicity by brassica vegetables. Chem Biol Interact 103: 79-129.

32. Mooney LA, Bell DA, Santella RM, et al. (1997) Contribution of genetic nutritional factors to DNA damage in heavy smokers. Carcinogenesis 18: 503-509. 